\title{
p38 MAPK contributes to angiotensin II-induced COX-2 expression in aortic fibroblasts from normotensive and hypertensive rats
}

\author{
Amada E. Beltrán ${ }^{\mathrm{a}}$, Ana M. Briones ${ }^{\mathrm{a}}$, Ana B. García-Redondo ${ }^{\mathrm{a}}$, \\ Cristina Rodríguez ${ }^{\mathrm{c}}$, Marta Miguel ${ }^{\mathrm{a}}$, Yolanda Álvarez ${ }^{\mathrm{a}}$, María J. Alonso ${ }^{\mathrm{a}, \mathrm{b}}$, \\ José Martínez-González ${ }^{\mathrm{c}}$ and Mercedes Salaices ${ }^{\mathrm{a}}$
}

Objective To investigate the effect of angiotensin II on cyclooxygenase-2 (COX-2) expression in aortic adventitial fibroblasts from normotensive [Wistar-Kyoto (WKY)] rats and spontaneously hypertensive rats (SHRs).

Methods Protein expression was determined by western blot, mRNA levels by real-time PCR, transcriptional activity by luciferase assays, superoxide anion $\left(\mathrm{O}_{2}{ }^{--}\right)$production by dihydroethidine fluorescence and prostaglandin $E_{2}$ by enzyme immunoassay.

Results Angiotensin II $(0.1 \mu \mathrm{mol} / \mathrm{l}, 0.5-6 \mathrm{~h})$ time dependently induced COX-2 protein expression, this effect being transient in fibroblasts from WKY rats and maintained over time in SHRs. Angiotensin II effect was abolished by valsartan $(1 \mu \mathrm{mol} / \mathrm{I})$, an angiotensin II type 1 receptor antagonist. Angiotensin II-induced prostaglandin $\mathrm{E}_{2}$ production was reduced by valsartan and the COX-2 inhibitor NS398 $(1 \mu \mathrm{mol} / \mathrm{l})$. Angiotensin II increased $\mathrm{O}_{2}{ }^{\bullet-}$ production more in SHR than WKY rats. This increase was reduced by apocynin $(30 \mu \mathrm{mol} / \mathrm{l})$ and allopurinol $(10 \mu \mathrm{mol} /$ I), respective nicotinamide adenine dinucleotide phosphate (NADPH) and xanthine oxidase inhibitors. However, angiotensin II-induced COX-2 expression was unaffected by apocynin, allopurinol, tempol $(1 \mathrm{mmol} / \mathrm{l})$ or catalase $(1000 \mathrm{U} / \mathrm{ml})$. Angiotensin II (2-30 $\mathrm{min})$ induced p38 mitogen-activated protein kinase (MAPK) phosphorylation, transiently in WKY rats but sustained in SHRs. The p38 inhibitor SB203580 (10 $\mu \mathrm{mol} / \mathrm{l})$ reduced angiotensin II-induced COX-2 protein and mRNA levels. The angiotensin II effect was not prevented by inhibition of

\section{Introduction}

There is increasing evidence indicating that the vascular adventitia, traditionally considered a structural support for the blood vessel, is a critical regulator of vessel wall function in health and disease [1-3]. Adventitia is primarily composed of fibroblasts, collagen and elastin fibers. Vascular fibroblasts produce substantial amounts of reactive oxygen species (ROS) that appear to be involved in the fibroblast proliferation, connective tissue deposition and changes in vascular tone [3] that occur in some cardiovascular diseases.
mRNA synthesis, and angiotensin II was unable to modulate COX-2 transcriptional activity.

Conc/usions Angiotensin II increases COX-2 expression in aortic fibroblasts through mechanisms including p38 MAPK pathway, independent of reactive oxygen species production and nonmediated by COX-2 transcriptional activity modulation. The sustained angiotensin-induced p38 MAPK activation in SHR cells might be related to the maintained COX-2 expression in this strain. $J$ Hypertens 27:142-154 (C) 2009 Wolters Kluwer Health | Lippincott Williams \& Wilkins.

Journal of Hypertension 2009, 27:142-154

Keywords: angiotensin, cyclooxygenase-2, fibroblasts, hypertension, mitogen-activated protein kinase

Abbreviations: COX, Cyclooxygenase; CREB, c-AMP regulatory element-binding protein; DHE, dihydroethidium; ERK1/2, extracellular signal-regulated kinases 1/2; JNK, c-Jun $\mathrm{NH}_{2}$-terminal kinases; MAPKs, mitogen-activated protein kinases; $\mathrm{PGE}_{2}$, prostaglandin $\mathrm{E}_{2}$; ROS, reactive oxygen species; SHRs, spontaneously hypertensive rats; VSMC, vascular smooth muscle cells; WKY, Wistar-Kyoto

aDepartamento de Farmacología y Terapéutica, Universidad Autónoma de Madrid, ' Departamento de Ciencias de la Salud III, Universidad Rey Juan Carlos, Alcorcón and ${ }^{\mathrm{C}}$ Centro de Investigación Cardiovascular (CSIC-ICCC), Hospital de la Santa Creu i Sant Pau, Barcelona, Spain

Correspondence to Mercedes Salaices, PhD, Facultad de Medicina, Departamento de Farmacología y Terapéutica, Universidad Autónoma de Madrid, 28029 Madrid, Spain

Tel: +34 91 4975378; fax: +34914975302;

e-mail: mercedes.salaices@uam.es

Received 9 May 2008 Revised 31 July 2008 Accepted 3 September 2008
Cyclooxygenase (COX) catalyzes the conversion of arachidonic acid to prostanoids, known as important inflammatory response mediators. In healthy blood vessels, most prostanoids are formed by the constitutive isoform of $\mathrm{COX}(\mathrm{COX}-1)$. However, these mediators may also be synthesized by the inducible isoform, COX-2, that can be induced by inflammatory agents such as lipopolysaccharide (LPS) or cytokines [4-6]. In fact, increased vascular COX-2 expression has been reported in pathological conditions associated with inflammatory processes, such as atherosclerosis or hypertension [7-10]. In addition, in 